\title{
A direct approach to the estimation of the origin of oestrogens and androgens in elderly men by comparison with hormone levels in postmenopausal women
}

\author{
Willem de Ronde ${ }^{1,2}$, Albert Hofman ${ }^{3}$, Huibert A P Pols ${ }^{1,3}$ and Frank H de Jong ${ }^{1}$ \\ ${ }^{1}$ Department of Internal Medicine, Erasmus Medical Center, Rotterdam, The Netherlands, ${ }^{2}$ Department of Endocrinology, Vrije Universiteit Medical \\ Center, Amsterdam, The Netherlands and ${ }^{3}$ Department of Epidemiology and Biostatistics, Erasmus Medical Center, Rotterdam, The Netherlands
}

(Correspondence should be addressed to W de Ronde, Department of Endocrinology, Vrije Universiteit Medical Center, PO Box 7057, 1007 MB Amsterdam, The Netherlands; Email: p.deronde@vumc.nl)

\begin{abstract}
Objective: The origin of oestrogens in men is only partly understood. From infusion studies with radioactively labelled hormones, we know that oestradiol (E2) and oestrone (E1) are either directly secreted by the testes and adrenal glands or peripherally produced from testicular or adrenal androgens. Design and methods: We determined E2, E1, androstenedione, testosterone and dehydroepiandrosterone sulphate (DHEAS) in 292 elderly men and 367 postmenopausal women. We considered postmenopausal women as men without testes, assuming that the postmenopausal ovary is not endocrinologically active and that the testes do not contribute to circulating levels of DHEAS. Subjects were stratified by DHEAS levels to adjust for differences in DHEAS levels between sexes. For men and women separately, mean levels of E2, E1, androstenedione and testosterone were calculated per DHEAS stratum. The relative direct and indirect contributions of the testes to steroid levels in men were calculated by the formula $\left[\left(\mathrm{C}_{\mathrm{m}}-\mathrm{C}_{\mathrm{f}}\right) / \mathrm{C}_{\mathrm{m}}\right] \times 100 \%$, in which $\mathrm{C}_{\mathrm{m}}$ and $\mathrm{C}_{\mathrm{f}}$ represent the mean concentrations of the steroid in men and women respectively.

Results: The relative contributions (\%) of the testes to hormone levels per DHEAS stratum $(<2,2-4$, $4-6$ and $>6 \mu \mathrm{mol} / \mathrm{l}$ ) respectively were, for E2, $72 \%, 60 \%, 52 \%$ and $44 \%$; for E1, $54 \%, 47 \%, 35 \%$ and $34 \%$; for androstenedione, $14 \%, 4 \%, 12 \%$ and $0 \%$; and, for testosterone, $88 \%, 88 \%, 87 \%$ and $83 \%$. Conclusions: We conclude that in elderly men dependent on DHEAS levels, $44-72 \%$ of E2 and $34-54 \%$ of E1 originate directly or indirectly from the testes.
\end{abstract}

European Journal of Endocrinology 152 261-268

\section{Introduction}

Since the description of oestrogen-resistant (1) and aromatase-deficient men $(2,3)$, it has been known that oestrogens are important sex hormones in men, just as in women. In men, oestrogens have an important role in bone maintenance, growth spurt induction, closure of epiphyses and inhibition of gonadotrophin release (4). From observations in oestrogen receptor alpha (ER $\alpha)$ knockout mice, it appears that oestrogens are also involved in the regulation of spermatogenesis (5). However, the origin of oestrogens in men is not easily assessed. Oestrone (E1) and oestradiol (E2) are secreted by adrenal glands and testes $(6,7)$. A substantial portion of circulating oestrogens, however, is derived from conversion of adrenal and testicular androgens in fat and muscle tissue by the aromatase enzyme $(8,9)$. Finally, the $17 \beta$-hydroxysteroid dehydrogenases, found throughout the body, can convert
E2 to E1 and testosterone to androstenedione, and vice versa (10).

Several studies were performed to quantify the sources of E1 and E2 in men, mainly by using isotope-labelled steroid infusion techniques followed by measurement of radioactive steroids in urine (11) or in plasma (8). Interpretation of data obtained by these methods is hampered by several factors. When we measure in urine, production rates can be reliably estimated only after complete retrieval of infused radioactivity, which often is not achieved. In addition, interconversion of both products and precursors makes it difficult to assess the importance of urinary data based on isotopic ratios in oestrogen conjugates. On the other hand, in measuring conversions in plasma, conversion rates are calculated on the basis of steadystate levels of radioactive precursors and their products during infusion, and this may require extremely long infusion times. Furthermore, interpretation of the 
results of such techniques assumes that steroid infusion does not interfere with the metabolism of the endogenous steroid hormones and that labelling of the steroids does not influence the catabolism of that hormone. The complex nature of these techniques makes it difficult to examine large numbers of subjects. More importantly, these studies inform about production and interconversion rates but give no information about the sites of hormone production.

Comparing plasma hormone levels before and after castration or adrenalectomy can also give an indication of the contribution of testes and adrenal glands to the oestrogen pool. Bilateral adrenalectomy is a rare procedure and is usually done to treat endocrine disorder, meaning that the preoperative hormone levels can hardly be considered normal. Bilateral orchiectomy is an accepted treatment for hormone-dependent prostatic carcinoma. Pre- and postoperative oestrogen measurements have been described by only two groups $(12,13)$ with different results. Suppression of adrenal steroid synthesis with exogenous glucocorticoids leads to suppression of endogenous oestrogen and testosterone synthesis, a result that will influence hypothalamus-pituitary-gonadal activity (14) and can therefore also lead to erroneous conclusions.

In view of the importance of oestrogens in men, the aim of this study was to estimate the contribution of the adrenal glands and the testes to the circulating pool of E1, E2, testosterone and androstenedione in a population-based sample of elderly men by using a different, simple, non-interventional approach. This approach has the advantage that the results obtained are not distorted by exogenous hormone administration and that estimates can be made of the relative contribution of the various sites of hormone production.

\section{Subjects and methods}

\section{Subjects}

All subjects were participants in the Rotterdam study, a population-based cohort study of determinants of chronic disabling diseases in the elderly. Details of this study have been described elsewhere (15). This study was approved by the medical ethics committee of the Erasmus Medical Centre, and all participants gave written, informed consent. Subjects using exogenous hormones, such as androgens, estrogens or dehydroepiandrosterone (DHEA), were excluded from this study. This was tested by asking the participants whether they used exogenous hormones, and by examining the medication boxes brought by the subjects on request on the day of examination. A total of 665 men and 741 women, aged 55-99 years, were randomly selected for hormone measurements. Of these subjects, 25 men and 22 women were excluded from analysis because of reported use of oral corticosteroids. No reliable data on the presence or absence of ovaries in the studied women were available. Non-fasting blood samples were drawn at the baseline examination in the research centre between 0830 and $1600 \mathrm{~h}$; the time of blood collection was recorded. The mean sampling time was $1122 \mathrm{~h}$ for women and $1125 \mathrm{~h}$ for men. For the collection of plasma, blood was sampled in $5 \mathrm{ml}$ tubes containing $0.5 \mathrm{ml}$ sodium citrate solution. Cells were removed by centrifugation, and the samples were stored at $-80^{\circ} \mathrm{C}$ until hormone measurement. The period of storage of frozen serum varied from 7.5 to 12.5 years. Because of the relatively small volumes of serum available, not all hormones could be determined in all samples. In 292 men and 367 women, all hormone measurements could be performed. Baseline characteristics such as age, body-mass index (BMI) and smoking in this subset were not different when compared with the overall group of subjects (data not shown).

\section{Hormone measurements}

Serum levels of testosterone, androstenedione, E1, E2, DHEA-sulphate (DHEAS) and sex hormone-binding globulin (SHBG) were estimated in 12 batches by coated-tube or double-antibody radioimmunoassays, purchased from Diagnostic Systems Laboratories (Webster, TX, USA). For E2 estimations, the ultrasensitive system was used. The results of these assays were compared with the results obtained with other commercial immunoassays, which in turn had been validated by comparison with in-house immunoassays, making use of steroid extraction and purification by column chromatography (testosterone (16), E2 (17), androstenedione (18), E1 (19) and DHEAS (20)). The same procedure was used for SHBG, where the in-house method used ammonium sulphate precipitation (21). Correlation coefficients varied from 0.925 for androstenedione to 0.980 for E2. Slopes of the regression lines were between 0.89 for E2 and 1.22 for DHEAS. The sensitivities of the assays, defined as the value representing the blank plus twice the standard deviation of the blank, were $4.8 \mathrm{pmol} / \mathrm{l}$ for E2 (22), $0.28 \mathrm{nmol} / \mathrm{l}$ for testosterone, $5 \mathrm{nmol} / \mathrm{l}$ for SHBG and $0.05 \mu \mathrm{mol} / \mathrm{l}$ for DHEAS. Steroids with the largest cross-reactivities in the various assays were E1 (2.4\%) and E2-3-glucuronide $(2.6 \%)$ for E2, E1 sulphate $(2.02 \%)$ and E2 $(1.25 \%)$ for E1, androsterone $(0.33 \%)$ and 17 -hydroxyprogesterone $(0.25 \%)$ for androstenedione, $5 \alpha$-dihydrotestosterone $(5.8 \%)$ and androstenedione $(2.3 \%)$ for testosterone, and DHEA (41\%) and androsterone (7.3\%) for DHEAS. Finally, further arguments supporting the validity of the estimation of $\mathrm{E} 2$ at the low level found in postmenopausal women by the present assay have been summarized by Goderie-Plomp et al. (22), who showed an increased risk of vertebral fractures in postmenopausal women with E2 levels in the lowest tertile. Because of the relatively small volumes of serum available, all values reported are single-sample 
estimations. Intra-assay coefficients of variation, determined on the basis of duplicate results of internal quality control (QC) serum pools with three different levels of each analyte, were below $15 \%$ for all assays, with the exception of E2 (18\%) and E1 (21\%). Since interassay variations were relatively large $(20-30 \%$, with the exception of testosterone (19\%) and SHBG (14\%)), the results of all batches were normalized by multiplying all concentrations within a batch by a factor, a method which equalized results for the internal quality-control pools. This was considered justified because the results of these pools and the mean results for male and female sera in each assay batch showed very similar patterns (23).

To estimate the relative contributions of the testes and the adrenals to the plasma pool of oestrogens, we considered postmenopausal women as men without testes. We assumed that the postmenopausal ovary is not endocrinologically active and that the testes do not contribute to circulating DHEAS levels. All subjects were stratified by DHEAS levels $(<2,2-4,4-6$ and $>6 \mu \mathrm{mol} / \mathrm{l})$ to adjust for differences in DHEAS levels between men and women. For men and women separately, mean age and BMI and mean levels of E2, E1, androstenedione and testosterone were calculated per DHEAS stratum. The relative contribution of the testes to hormone levels in men was calculated for each stratum of DHEAS levels by the formula $\left[\left(\mathrm{C}_{\mathrm{m}}-\mathrm{C}_{\mathrm{f}}\right) / \mathrm{C}_{\mathrm{m}}\right] \times 100 \%$, in which $\mathrm{C}_{\mathrm{m}}$ and $\mathrm{C}_{\mathrm{f}}$ represent the mean concentrations of hormones in men and women respectively.

\section{Statistics}

All analyses were done with SPSS 9.0 software (SPSS Inc., Chicago, IL, USA). A $P$ value of $<0.05$ was considered significant. For all subgroups, the distribution of the hormone levels was tested for normality by the Kolmogorov-Smirnov test. Results are expressed as median, mean, and S.D. or S.E.M. Differences between men and women for normally distributed variables were tested for significance by Student's t-test, and for not normally distributed variables by the Mann-Whitney U-test. For men and women separately, Spearman's correlation coefficients were calculated between the concentrations of the hormones studied, age and BMI.

To study the impact of sampling time on hormone levels, sampling time was divided into quartiles, and mean levels of all hormones and SHBG were calculated per quartile for men and women separately. By analysis of variance, sampling-time-related differences in mean hormone levels were tested for significance.

\section{Results}

Table 1 summarizes the characteristics of the studied men and women. Men were slightly younger and had lower BMI than women. As expected, testosterone
Table 1 Baseline characteristics of studied men and women (median/mean \pm S.D.).

\begin{tabular}{lcc}
\hline & Men & Women \\
\hline$n$ & 292 & 367 \\
Age (years) & $68.7 / 69.7 \pm 8.06$ & $71.2 / 71.6 \pm 8.91$ \\
BMl $\left(\mathrm{kg} / \mathrm{m}^{2}\right)$ & $25.8 / 25.8 \pm 3.00$ & $26.4 / 26.6 \pm 3.95$ \\
E2 $(\mathrm{pmol} / \mathrm{l})$ & $44.9 / 46.7 \pm 22.8$ & $13.9 / 16.1 \pm 13.8$ \\
$\mathrm{E} 1(\mathrm{pmol} / \mathrm{l})$ & $85.5 / 88.3 \pm 42.9$ & $41.5 / 43.0 \pm 31.1$ \\
Androstenedione $(\mathrm{nmol} / \mathrm{l})$ & $3.84 / 4.18 \pm 1.75$ & $3.20 / 3.46 \pm 1.73$ \\
Testosterone $(\mathrm{nmol} / \mathrm{l})$ & $11.3 / 11.3 \pm 4.01$ & $1.22 / 1.31 \pm 0.80$ \\
DHEAS $(\mu \mathrm{mol} / \mathrm{l})$ & $4.10 / 4.86 \pm 3.13$ & $2.17 / 2.72 \pm 1.96$ \\
SHBG $(\mathrm{nmol} / \mathrm{l})$ & $33.8 / 36.3 \pm 14.5$ & $43.4 / 45.9 \pm 18.6$ \\
\hline
\end{tabular}

levels were much higher in men, but also levels of E1 and E2 were respectively two and three times higher than those in postmenopausal women. The concentrations of the adrenal androgens DHEAS and androstenedione were also higher in men. The mean concentration of SHBG was higher in women, resulting in a higher percentage of testosterone and E2 bound to SHBG $(P<0.001$ for all variables). After division into quartiles for sampling time, mean hormone and SHBG levels were not found to be significantly different between quartiles for men and women separately, suggesting that differences in sampling time did not influence results (data not shown). Tables 2 and 3 show Spearman's correlation coefficients for the relations between the levels of hormones, SHBG, age and BMI in men and women respectively. The levels of all hormones were weakly but significantly interrelated in both men and women. The correlations between SHBG and hormones were weak or absent. In both men and women, older age was associated with significantly lower levels of DHEAS, androstenedione and E2 but higher levels of SHBG. Age and testosterone were inversely associated in men only. Higher BMI was associated with lower SHBG in men and women. BMI was associated with higher oestrogen and testosterone levels in women, but not in men. In contrast, higher BMI was weakly associated with lower testosterone levels in men. The mean levels of hormones per DHEAS stratum for men and women are given in Table 4 . Women were overrepresented in the lower DHEAS strata, whereas men were overrepresented in the higher DHEAS strata. Hormone levels in all subgroups were normally distributed except for E2 in women in the DHEAS of $<2$ category. In this subgroup, there was an overrepresentation of very low E2 levels.

Mean age and BMI per DHEAS stratum for men and women are given in Table 5. Both women and men in higher DHEAS subgroups were significantly younger $(P<0.001)$, but the mean ages of men and women per DHEAS stratum were similar. DHEAS and BMI were not significantly associated.

Figure 1 shows the calculated relative contributions of the testes and adrenal glands to the plasma levels 
Table 2 Spearman's correlation coefficients between hormone levels, age and BMI in 292 men.

\begin{tabular}{|c|c|c|c|c|c|c|c|}
\hline & E1 & Androstenedione & Testosterone & SHBG & DHEAS & Age & BMI \\
\hline $\begin{array}{l}\text { E2 } \\
\text { E1 } \\
\text { Androstenedione } \\
\text { Testosterone } \\
\text { SHBG } \\
\text { DHEAS } \\
\text { Age }\end{array}$ & $0.47^{\star \star \star}$ & $\begin{array}{l}0.27^{\star \star \star} \\
0.18^{\star \star}\end{array}$ & $\begin{array}{l}0.37^{\star \star \star} \\
0.28^{\star \star *} \\
0.32^{\star \star \star}\end{array}$ & $\begin{array}{r}-0.08 \\
-0.13^{\star} \\
0.14^{\star} \\
0.12^{\star}\end{array}$ & $\begin{array}{l}0.35^{\star \star \star} \\
0.29^{\star \star \star} \\
0.30^{\star \star \star} \\
0.28^{\star \star \star} \\
-0.07\end{array}$ & $\begin{array}{l}-0.14^{\star \star} \\
-0.06 \\
-0.15^{\star \star} \\
-0.26^{\star \star \star} \\
0.22^{\star \star \star} \\
-0.32^{\star \star \star}\end{array}$ & $\begin{array}{l}0.06 \\
0.05 \\
0.03 \\
-0.12^{\star \star} \\
-0.23^{\star \star \star} \\
-0.04 \\
-0.09^{\star}\end{array}$ \\
\hline
\end{tabular}

${ }^{\star} P<0.05 ;{ }^{* *} P<0.01 ;{ }^{* \star *} P<0.001$.

Table 3 Spearman's correlation coefficients between hormone levels, age and BMI in 367 women.

\begin{tabular}{|c|c|c|c|c|c|c|c|}
\hline & E1 & Androstenedione & Testosterone & SHBG & DHEAS & Age & BMI \\
\hline E2 & $0.47^{\star \star \star}$ & $0.42^{\star * *}$ & $0.42^{\star \star \star}$ & $-0.26^{\star *}$ & $0.43^{\star \star *}$ & $-0.17^{\star \star \star}$ & $0.24^{\star \star \star}$ \\
\hline E1 & & $0.22^{\star \star \star}$ & $0.41^{\star \star \star}$ & $-0.34^{\star *}$ & $0.31^{\star \star \star}$ & -0.04 & $0.28^{\star \star \star}$ \\
\hline Androstenedione & & & $0.53^{\star \star *}$ & $-0.12^{\star}$ & $0.40^{* * *}$ & $-0.13^{\star \star}$ & 0.01 \\
\hline Testosterone & & & & $-0.17^{\star \star}$ & $0.30^{\star \star \star}$ & -0.07 & $0.15^{\star \star \star}$ \\
\hline SHBG & & & & & $-0.22^{\star \star}$ & $0.30^{\star \star \star}$ & $-0.30^{\star \star \star}$ \\
\hline DHEAS & & & & & & $-0.32^{\star \star \star}$ & 0.03 \\
\hline Age & & & & & & & 0.07 \\
\hline
\end{tabular}

${ }^{\star} P<0.05 ;{ }^{* *} P<0.01 ;{ }^{* \star *} P<0.001$.

Table 4 Hormone levels per DHEAS stratum ( $\mu \mathrm{mol} / \mathrm{l})$ in men and women (mean \pm S.E.M.).

\begin{tabular}{llrcrrrr}
\hline DHEAS stratum & & $\boldsymbol{n}$ & DHEAS $(\mu \mathrm{mol} / \mathrm{l})$ & E2 $(\mathrm{pmol} / \mathrm{l})$ & $\mathbf{E 1}(\mathrm{pmol} / \mathrm{l})$ & Androstenedione $(\mathrm{nmol} / \mathrm{l})$ & Testosterone $(\mathrm{nmol} / \mathrm{l})$ \\
\hline$<2$ & Men & 36 & $1.38 \pm 0.08$ & $40.9 \pm 3.77$ & $74.7 \pm 5.14$ & $3.39 \pm 0.17$ & $9.45 \pm 0.52$ \\
& Women & 167 & $1.19 \pm 0.04$ & $11.6 \pm 0.93$ & $34.5 \pm 1.97$ & $2.92 \pm 0.10$ & $1.13 \pm 0.05$ \\
$2-4$ & Men & 107 & $2.93 \pm 0.06$ & $40.7 \pm 1.72$ & $80.1 \pm 3.29$ & $3.82 \pm 0.13$ & $10.7 \pm 0.32$ \\
$4-6$ & Women & 121 & $2.87 \pm 0.05$ & $16.2 \pm 1.19$ & $42.6 \pm 2.81$ & $3.61 \pm 0.13$ & $1.30 \pm 0.06$ \\
& Men & 67 & $5.01 \pm 0.07$ & $48.9 \pm 3.41$ & $90.6 \pm 5.98$ & $4.51 \pm 0.30$ & $11.7 \pm 0.59$ \\
& Women & 59 & $4.82 \pm 0.07$ & $23.6 \pm 1.54$ & $58.9 \pm 4.23$ & $3.98 \pm 0.25$ & $1.57 \pm 0.10$ \\
& Men & 82 & $8.79 \pm 0.32$ & $55.5 \pm 2.34$ & $103 \pm 5.33$ & $4.72 \pm 0.18$ & $12.5 \pm 0.45$ \\
& Women & 20 & $8.27 \pm 0.30$ & $31.2 \pm 3.87$ & $68.2 \pm 8.95$ & $5.47 \pm 0.71$ & $2.12 \pm 0.24$ \\
\hline
\end{tabular}

of E2, E1, androstenedione and testosterone in men, stratified by DHEAS level. The relative contribution (\%) of the testes to hormone levels per DHEAS stratum $(<2,2-4$, $4-6$ and $>6 \mu \mathrm{mol} / \mathrm{l}$ ) respectively were, for $\mathrm{E} 2,72 \%$, $60 \%, 52 \%$ and $44 \%$; for E1, $54 \%, 47 \%, 35 \%$ and $34 \%$;

Table 5 Age and BMI per DHEAS stratum ( $\mu \mathrm{mol} / \mathrm{l})$ in men and women (mean \pm S.E.M.).

\begin{tabular}{llrlc}
\hline DHEAS stratum & & $\boldsymbol{n}$ & \multicolumn{1}{c}{ Age } & BMI \\
\hline$<2$ & Men & 36 & $74.6 \pm 1.62$ & $25.8 \pm 0.46$ \\
& Women & 167 & $74.3 \pm 0.69$ & $26.7 \pm 0.31$ \\
$2-4$ & Men & 107 & $71.0 \pm 0.73$ & $26.1 \pm 0.26$ \\
& Women & 121 & $70.7 \pm 0.72$ & $26.5 \pm 0.37$ \\
$4-6$ & Men & 67 & $68.6 \pm 0.91$ & $25.9 \pm 0.43$ \\
& Women & 59 & $68.1 \pm 1.2$ & $26.6 \pm 0.52$ \\
$>6$ & Men & 82 & $66.7 \pm 0.77$ & $25.5 \pm 0.35$ \\
& Women & 20 & $65.8 \pm 1.9$ & $27.4 \pm 0.93$ \\
\hline
\end{tabular}

for androstenedione, $14 \%, 4 \%, 12 \%$ and $0 \%$; and for testosterone, $88 \%, 88 \%, 87 \%$ and $83 \%$.

\section{Discussion}

When postmenopausal women are considered as elderly men without testes, it is possible to calculate the relative contribution of the adrenal glands and the testes to peripheral concentrations of sex steroids in elderly men by the formula given in the Methods section. According to our calculations, up to $56 \%$ of E2, $66 \%$ of $\mathrm{E} 1$ and $17 \%$ of testosterone may have its direct or indirect origin in the adrenal glands of elderly men (Fig. 1). The testes contribute only a little to peripheral androstenedione levels (maximum 14\%). These estimates agree with the results of earlier experiments using radiolabelled hormone infusion techniques. MacDonald et al. (24) calculated that the daily urinary E2 excretion in men aged 26-35 years originates from direct secretion by the testes $(13 \%)$ 

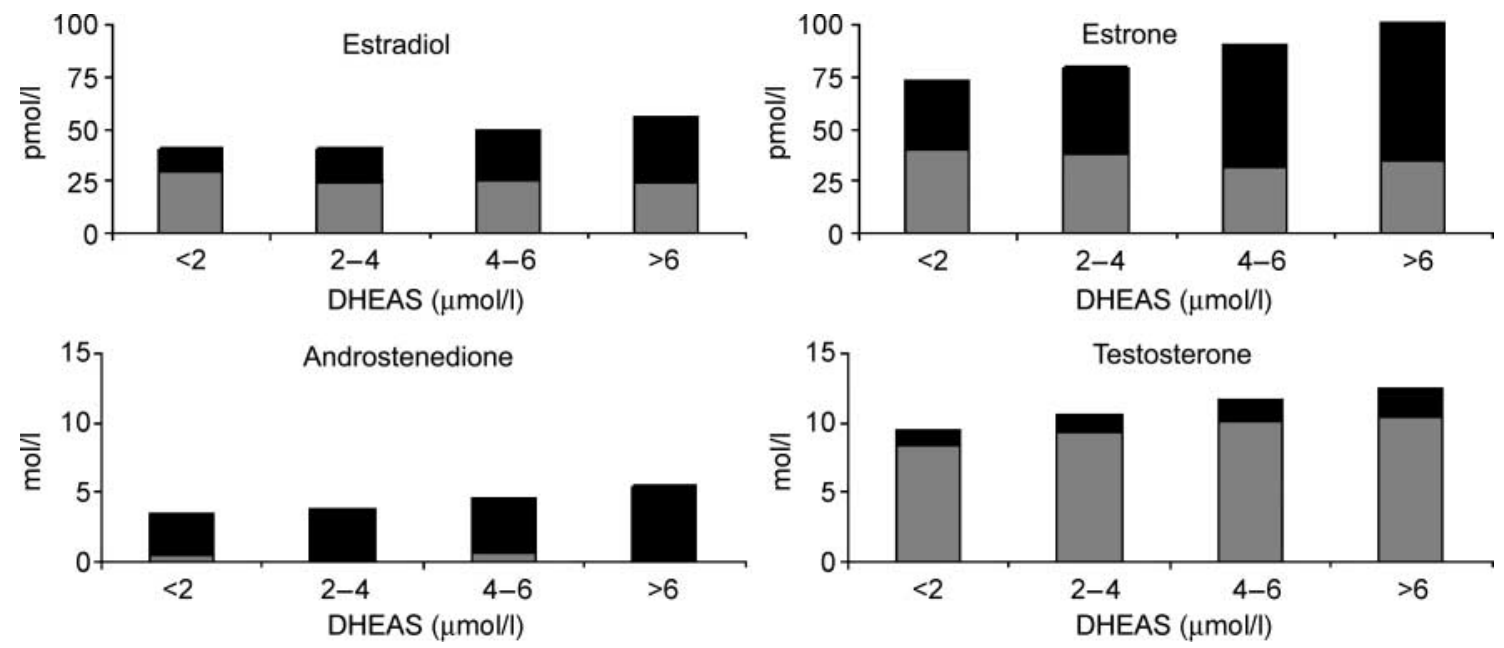

Figure 1 DHEAS-stratified, calculated relative contributions of the testes (grey) and adrenals (black) to peripheral concentrations of oestradiol (E2), oestrone (E1), androstenedione and testosterone.

and from peripheral production from circulating testosterone $(38 \%)$ or androstenedione $(49 \%)$. Urinary E1 is only peripherally produced via conversion of testosterone $(32 \%)$ or androstenedione $(68 \%)$. However, the nature of their study precludes conclusions about the production sites of testosterone and androstenedione. Our study provides evidence that circulating testosterone is mainly produced by the testes, while the adrenal glands are the main source of circulating androstenedione. If we assume that the conversion rates from androgens to estrogens in young and elderly men are similar, the contribution by the testes to daily E2 and E1 production may be estimated to be $50 \%$ and 33\% after adjustment for the small contribution of the testes and the adrenal glands to the androstenedione and testosterone pools respectively.

Our calculations are based on several assumptions. First, we assumed that the postmenopausal ovary is not endocrinologically active. This is supported by the report of Couzinet et al. (25), who found testosterone and androstenedione to be below or close to the limit of detection of their assay in postmenopausal women with adrenal insufficiency. However, other reports indicate that the postmenopausal ovary can be an important source of androgens in women. Surgical castration of postmenopausal women resulted in a mean decrease of circulating testosterone levels of $46 \%$ (26) and 38\% (27). The mean testosterone level in ovariectomized women was reported to be $40 \%$ lower than concentrations in intact postmenopausal women (28). Pharmacological suppression of postmenopausal ovarian hormone synthesis also resulted in significantly lower peripheral testosterone levels $(29,30)$. Moreover, ovarian venous testosterone levels are higher than peripheral testosterone levels $(31-33)$. This would mean that our model overestimates the adrenal contribution to peripheral sex steroid levels in men. No reliable data on the presence or absence of ovaries in our studied women were available; therefore, we were not able to make proper adjustments. However, although the androgen production of the postmenopausal ovary might be significant, it is small in comparison to the testicular production in men. Therefore, adjustment for the ovarian contribution to circulating levels of testosterone (38\%) and E2 (6\%), as reported by Sluijmer et al. (34) on the basis of the formulas $\left(\mathrm{C}_{\mathrm{m}}-\mathrm{C}_{\mathrm{f}-38 \%}\right) / \mathrm{C}_{\mathrm{m}}$ for testosterone and $\left(\mathrm{C}_{\mathrm{m}}-\mathrm{C}_{\mathrm{f}-6 \%}\right) / \mathrm{C}_{\mathrm{m}}$ for E2), will lead to a maximal increment of the testicular contribution to peripheral testosterone and E2 concentrations of $7 \%$ and $3 \%$ respectively for every DHEAS stratum.

Although the testes produce no DHEAS but some androstenedione and DHEA (35), we assumed that the testes do not contribute to the plasma pool of DHEAS. However, Stege et al. (36) found DHEAS levels 6 months after orchidectomy to be $17 \%$ lower than preoperative levels. In contrast, Parker et al. (37) found no difference between pre- and postorchidectomy DHEAS levels. If the testes contributed to DHEAS levels, comparison of men and postmenopausal women after stratification for DHEAS will show that the relative contribution of the adrenal glands to plasma concentrations of sex hormones is slightly overestimated. A testicular contribution to peripheral DHEAS levels of $17 \%$, as found by Stege et al. (38), for example, will lead to a calculated maximal increase of testicular contribution in our model of 3\% for E2, 3\% for E1, $4 \%$ for androstenedione and 0\% for testosterone per DHEAS stratum (DHEAS $\mathrm{m}_{\mathrm{m}-17 \%}$ before stratification).

The women in our study population had significantly higher levels of SHBG. In normal men and women, 40$65 \%$ of circulating testosterone and $20-40 \%$ of circulating E2 is bound to SHBG. Binding of E1 and androstenedione to SHBG is less than 20\% (39). SHBG decreases the metabolic clearance rate (MCR) of bound hormones (40). With similar production rates, 
this will lead to higher plasma levels of testosterone (and probably also of E2) in women compared with men. On top of that, the conversion rate of testosterone to androstenedione is linearly correlated with the nonSHBG-bound fraction of testosterone, but not with total testosterone (41). As shown in Tables 2 and 3, higher SHBG levels are not or are only weakly associated with higher levels of testosterone or E2 in women and men. In view of the small difference in mean SHBG level between men and women (less than $10 \mathrm{nmol} / \mathrm{l}$ ) and the weak associations between SHBG, E2 and testosterone (Tables 2 and 3), it is likely that the effects of SHBG on circulating levels of hormone are small. Nevertheless, we cannot rule out that this has influenced our estimates.

It is unlikely that sex, either related or not related to differences in SHBG levels, caused a difference in the metabolism of DHEA and DHEAS, since the metabolic clearance rate of these hormones is reported to be similar in men and women $(42,43)$.

Age is an important determinant of hormone levels in both men and women. As is evident from Tables 2, 3 and 5, ageing is associated with significantly lower DHEAS levels in both sexes, a phenomenon also reported by others (44). Stratification by DHEAS level therefore automatically results in stratification by age (Table 5), and results obtained after stratification might thus be biased by age effects; comparison of men and women with similar DHEAS levels but totally different age might be inappropriate. However, age differences between men and women per DHEAS stratum were small and therefore not likely to influence the results of the calculations. Moreover, age was not independently associated with levels of E2 or androstenedione and was only weakly associated with higher E1 and lower testosterone levels after adjustment for DHEAS level in both men and women (data not shown).

Adipose tissue is important for androgen aromatization in men and women. Obesity is clearly associated with increased androgen aromatization $(45,46)$. The percentage of body fat is higher in women than men and increases with age in both sexes $(47,48)$. The reported age-related increase in androgen aromatization might be attributed to this phenomenon (49). These sex- and age-related changes in body composition might have biased our estimates. However, Longcope et al. (50) estimated that adipose tissue accounts for only $10-15 \%$ of the extragonadal androgen aromatization and that muscle tissue is also an important source of peripheral oestrogen production. In vitro studies show that muscle tissue is almost equally effective in converting androgens to oestrogens (51). It is therefore questionable whether changes or differences in the fat mass/muscle mass ratio will result in changes in aromatization rate. Moreover, older age appears to be associated with increased aromatase expression in adipose tissue $(52,53)$, suggesting that not the age-related change in body composition but the age-related increase of aromatase expression might explain the increased androgen aromatization in older subjects. Whatever the cause, the androgen to oestrogen conversion rate appears to be determined by age and BMI. Since age and BMI in our study were similar for men and women in every DHEAS stratum (Table 5), we believe that these parameters did not bias our estimates much.

The time of blood collection ranged from 0830 to $1600 \mathrm{~h}$, but mean sampling times were similar for men and women. It is well known that in young men androstenedione and testosterone, but not DHEAS, have a circadian rhythm $(54,55)$, although the daily variation in hormone concentration appears to decrease with age $(56,57)$. Because of the high mean age of our population and the large number of subjects, we believe that differences in sampling time did not have a major influence on the results. This was confirmed by our observation that, after division into sampling time quartiles, mean hormone and SHBG levels between quartiles were not significantly different.

Both the steroid infusion techniques and our approach have their limitations, as previously mentioned. The results obtained, however, are similar. Our results also show that the relative contribution of adrenal glands and testes to circulating levels of sex steroids is highly dependent on the hormone-secreting activity of these glands. Although a correlation between DHEAS and testosterone levels was found, the balance of these hormones can vary widely between individuals. Additionally, the rate of conversion of androgens to oestrogens can vary according to the amount of fat mass $(58,59)$, age $(60-62)$, SHBG concentration (63) and liver disease (64). The large number of men in this study population makes the estimates relatively insensitive to interindividual variations in these variables. Another advantage of our approach is that it is noninterventional, so that the delicate and complex equilibrium between hormones is not disturbed. Finally, the population-based nature of the study makes the results applicable to a broad range of elderly men.

In conclusion, our results show that testes and adrenal glands in elderly men both contribute significantly to the circulating levels of oestrogens. The mean contributions of the testes to peripheral E2 and E1 levels in elderly men are $57 \%$ and $43 \%$ respectively, the remainder being of adrenal origin. When individual subjects are concerned, these percentages are dependent on the individual balance between testicular and adrenal activity and interindividual differences in the conversion of androgens to oestrogens. With the growing body of evidence on the role of estrogens in males, this study suggests that surgical or pharmacological suppression of gonadal or adrenal function in men can lower oestrogen levels significantly and can therefore contribute to changes in the response of oestrogen-sensitive target tissues. 


\section{References}

1 Smith EP, Boyd J, Frank GR, Takahashi H, Cohen RM, Specker B, Williams TC, Lubahn DB \& Korach KS. Estrogen resistance caused by a mutation in the estrogen-receptor gene in a man. New England Journal of Medicine 1994331 1056-1061.

2 Morishima A, Grumbach MM, Simpson ER, Fisher C \& Qin K. Aromatase deficiency in male and female siblings caused by a novel mutation and the physiological role of estrogens. Journal of Clinical Endocrinology and Metabolism $1995803689-3698$.

3 Carani C, Qin K, Simoni M, Faustini-Fustini M, Serpente S, Boyd J, Korach KS \& Simpson ER. Effect of testosterone and estradiol in a man with aromatase deficiency. New England Journal of Medicine 1997337 91-95.

4 de Ronde W, Pols HA, Van Leeuwen JP \& de Jong FH. The importance of oestrogens in males. Clinical Endocrinology $2003 \mathbf{5 8}$ $529-542$.

5 O'Donnell L, Robertson KM, Jones ME \& Simpson ER. Estrogen and spermatogenesis. Endocrine Reviews 200122 289-318.

6 Saez JM, Morera AM, Dazord A \& Bertrand J. Adrenal and testicular contribution to plasma oestrogens. Journal of Endocrinology $19725541-49$.

7 Scholler R, Nahoul K, Castanier M, Rotman J \& Salat-Baroux J. Testicular secretion of conjugated and unconjugated steroids in normal adults and in patients with varicocele. Baseline levels and time-course response to hCG administration. Journal of Steroid Biochemistry 198420 203-215.

8 Baird DT, Horton R, Longcope C \& Tait JF. Steroid dynamics under steady-state conditions. Recent Progress in Hormone Research 1969 25 611-664.

9 MacDonald PC, Madden JD, Brenner PF, Wilson JD \& Siiteri PK. Origin of estrogen in normal men and in women with testicular feminization. Journal of Clinical Endocrinology and Metabolism 197949 905-916.

10 Adamski J \& Jakob FJ. A guide to 17beta-hydroxysteroid dehydrogenases. Molecular Cell Endocrinology 2001 171 1-4.

11 MacDonald PC, Madden JD, Brenner PF, Wilson JD \& Siiteri PK. Origin of estrogen in normal men and in women with testicular feminization. Journal of Clinical Endocrinology and Metabolism 197949 905-916.

12 Bartsch W, Horst HJ, Becker H \& Nehse G. Sex hormone binding globulin binding capacity, testosterone, 5alpha-dihydrotestosterone, oestradiol and prolactin in plasma of patients with prostatic carcinoma under various types of hormonal treatment. Acta Endocrinologica 197785 650-664.

13 Fiet J, Villette JM, Bertagna C, de Gery A, Hucher M, Husson JM \& Raynaud JP. Plasma hormone levels before and after orchiectomy in prostate cancer patients. Progress in Clinical and Biological Research 1987243 33-44.

14 Veldhuis JD, Lizarralde G \& Iranmanesh A. Divergent effects of short term glucocorticoid excess on the gonadotropic and somatotropic axes in normal men. Journal of Clinical Endocrinology and Metabolism 1992 74 96-102.

15 Hofman A, Grobbee DE, de Jong PT \& Van den Ouweland FA. Determinants of disease and disability in the elderly: the Rotterdam Elderly Study. European Journal of Epidemiology 19917 $403-422$.

16 Verjans HL, Cooke BA, de Jong FH, de Jong CM \& Van der Molen $\mathrm{HJ}$. Evaluation of a radioimmunoassay for testosterone estimation. Journal of Steroid Biochemistry 19734 665-676.

17 de Jong FH, Hey AH \& van der Molen HJ. Effect of gonadotrophins on the secretion of oestradiol-17 $\beta$ and testosterone by the rat testis. Journal of Endocrinology 197357 277-284.

18 Frolich M, Brand EC \& Van Hall EV. Serum levels of unconjugated aetiocholanolone androstenedione, testosterone, dehydroepiandrosterone, aldosterone, progesterone and oestrogens during the normal menstrual cycle. Acta Endocrinologica $1976 \mathbf{8 1}$ $548-562$.

19 Van Landeghem AA, Poortman J, Deshpande N, Di Martino L, Tarquini A \& Thijssen JH. Plasma concentration gradient of steroid hormones across human mammary tumours in vivo. Journal of Steroid Biochemistry 198114 741-747.

20 de Jong FH \& van der Molen HJ. Determination of dehydroepiandrosterone and dehydroepiandrosterone sulphate in human plasma using electron capture detection of 4-androstene-3,6,17trione after gas-liquid chromatography. Journal of Endocrinology $197253461-474$.

21 de Jong FH, Oishi K, Hayes RB, Bogdanowicz JF, Raatgever JW, van der Maas PJ, Yoshida O \& Schroeder FH. Peripheral hormone levels in controls and patients with prostatic cancer or benign prostatic hyperplasia: results from the Dutch-Japanese case-control study. Cancer Research 199151 3445-3450.

22 Goderie-Plomp HW, van der KM, de Ronde W, Hofman A, de Jong FH \& Pols HA. Endogenous sex hormones, sex hormone-binding globulin, and the risk of incident vertebral fractures in elderly men and women: the Rotterdam Study. Journal of Clinical Endocrinology and Metabolism 200489 3261-3269.

23 Hak AE, Witteman JC, de Jong FH, Geerlings MI, Hofman A \& Pols HA. Low levels of endogenous androgens increase the risk of atherosclerosis in elderly men: the Rotterdam study. Journal of Clinical Endocrinology and Metabolism $2002 \quad 87$ 3632-3639.

24 MacDonald PC, Madden JD, Brenner PF, Wilson JD \& Siiteri PK. Origin of estrogen in normal men and in women with testicular feminization. Journal of Clinical Endocrinology and Metabolism 197949 905-916.

25 Couzinet B, Meduri G, Lecce MG, Young J, Brailly S, Loosfelt H, Milgrom E \& Schaison G. The postmenopausal ovary is not a major androgen-producing gland. Journal of Clinical Endocrinology and Metabolism 200186 5060-5066.

26 Judd HL, Lucas WE \& Yen SS. Effect of oophorectomy on circulating testosterone and androstenedione levels in patients with endometrial cancer. American Journal of Obstetrics and Gynecology 1974 $118793-798$.

27 Sluijmer AV, Heineman MJ, de Jong FH \& Evers JL. Endocrine activity of the postmenopausal ovary: the effects of pituitary down-regulation and oophorectomy. Journal of Clinical Endocrinology and Metabolism 199580 2163-2167.

28 Laughlin GA, Barrett-Connor E, Kritz-Silverstein D \& von Muhlen D. Hysterectomy, oophorectomy, and endogenous sex hormone levels in older women: the Rancho Bernardo Study. Journal of Clinical Endocrinology and Metabolism 200085 645-651.

29 Dowsett M, Cantwell B, Lal A, Jeffcoate SL \& Harris AL. Suppression of postmenopausal ovarian steroidogenesis with the luteinizing hormone-releasing hormone agonist goserelin. Journal of Clinical Endocrinology and Metabolism 198866 672-677.

30 Rabinovici J, Rothman P, Monroe SE, Nerenberg C \& Jaffe RB. Endocrine effects and pharmacokinetic characteristics of a potent new gonadotropin-releasing hormone antagonist (Ganirelix) with minimal histamine-releasing properties: studies in postmenopausal women. Journal of Clinical Endocrinology and Metabolism 199275 1220-1225.

31 Longcope C, Hunter R \& Franz C. Steroid secretion by the postmenopausal ovary. American Journal of Obstetrics and Gynecology $1980138564-568$.

32 Sluijmer AV, Heineman MJ, de Jong FH \& Evers JL. Endocrine activity of the postmenopausal ovary: the effects of pituitary down-regulation and oophorectomy. Journal of Clinical Endocrinology and Metabolism $1995802163-2167$.

33 Judd HL, Judd GE, Lucas WE \& Yen SS. Endocrine function of the postmenopausal ovary: concentration of androgens and estrogens in ovarian and peripheral vein blood. Journal of Clinical Endocrinology and Metabolism 197439 1020-1024.

34 Sluijmer AV, Heineman MJ, de Jong FH \& Evers JL. Endocrine activity of the postmenopausal ovary: the effects of pituitary down-regulation and oophorectomy. Journal of Clinical Endocrinology and Metabolism 199580 2163-2167.

35 Scholler R, Nahoul K, Castanier M, Rotman J \& Salat-Baroux J. Testicular secretion of conjugated and unconjugated steroids in normal adults and in patients with varicocele. Baseline levels 
and time-course response to hCG administration. Journal of Steroid Biochemistry 198420 203-215.

36 Stege R, Eriksson A, Henriksson P \& Carlstrom K. Orchidectomy or oestrogen treatment in prostatic cancer: effects on serum levels of adrenal androgens and related steroids. International Journal of Andrology 198710 581-587.

37 Parker L, Lai M, Wolk F, Lifrak E, Kim S, Epstein L, Hadley D \& Miller J. Orchiectomy does not selectively increase adrenal androgen concentrations. Journal of Clinical Endocrinology and Metabolism $198459547-550$.

38 Stege R, Eriksson A, Henriksson P \& Carlstrom K. Orchidectomy or oestrogen treatment in prostatic cancer: effects on serum levels of adrenal androgens and related steroids. International Journal of Andrology 198710 581-587.

39 Dunn JF, Nisula BC \& Rodbard D. Transport of steroid hormones: binding of 21 endogenous steroids to both testosterone-binding globulin and corticosteroid-binding globulin in human plasma Journal of Clinical Endocrinology and Metabolism 198153 58-68.

40 Vermeulen A \& Ando S. Metabolic clearance rate and interconversion of androgens and the influence of the free androgen fraction. Journal of Clinical Endocrinology and Metabolism $1979 \mathbf{4 8}$ $320-326$.

41 Vermeulen A \& Ando S. Metabolic clearance rate and interconversion of androgens and the influence of the free androgen fraction. Journal of Clinical Endocrinology and Metabolism $1979 \mathbf{4 8}$ $320-326$.

42 Bird CE, Masters V \& Clark AF. Dehydroepiandrosterone sulfate: kinetics of metabolism in normal young men and women. Clinical and Investigative Medicine 19847 119-122.

43 Longcope C. Metabolism of dehydroepiandrosterone. Annals of the New York Academy of Sciences 1995 774 143-148.

44 Laughlin GA \& Barrett-Connor E. Sexual dimorphism in the influence of advanced aging on adrenal hormone levels: the Rancho Bernardo Study. Journal of Clinical Endocrinology and Metabolism $2000853561-3568$.

45 Kley HK, Deselaers T, Peerenboom H \& Kruskemper HL. Enhanced conversion of androstenedione to estrogens in obese males. Journal of Clinical Endocrinology and Metabolism 198051 1128-1132.

46 Kley HK, Edelmann P \& Kruskemper HL. Relationship of plasma sex hormones to different parameters of obesity in male subjects. Metabolism 198029 1041-1045.

47 Guo SS, Zeller C, Chumlea WC \& Siervogel RM. Aging, body composition, and lifestyle: the Fels Longitudinal Study. American Journal of Clinical Nutrition $1999 \mathbf{7 0}$ 405-411.

48 Schutz Y, Kyle UU \& Pichard C. Fat-free mass index and fat mass index percentiles in Caucasians aged 18-98 y. International Journal of Obesity-Related Metabolism Disorders 200226 953-960.

49 Hemsell DL, Grodin JM, Brenner PF, Siiteri PK \& MacDonald PC. Plasma precursors of estrogen. II. Correlation of the extent of conversion of plasma androstenedione to estrone with age. Journal of Clinical Endocrinology and Metabolism 197438 476-479.

50 Longcope C, Pratt JH, Schneider SH \& Fineberg SE. Aromatization of androgens by muscle and adipose tissue in vivo. Journal of Clinical Endocrinology and Metabolism 197846 146-152.
51 Matsumine H, Hirato K, Yanaihara T, Tamada T \& Yoshida M. Aromatization by skeletal muscle. Journal of Clinical Endocrinology and Metabolism 198663 717-720.

52 Bulun SE \& Simpson ER. Competitive reverse transcription-polymerase chain reaction analysis indicates that levels of aromatase cytochrome $\mathrm{P} 450$ transcripts in adipose tissue of buttocks, thighs, and abdomen of women increase with advancing age. Journal of Clinical Endocrinology and Metabolism 199478 428-432.

53 Cleland WH, Mendelson CR \& Simpson ER. Effects of aging and obesity on aromatase activity of human adipose cells. Journal of Clinical Endocrinology and Metabolism 198560 174-177.

54 Sjoberg B, de la Torre B, Hedman M, Falkay G \& Diczfalusy E. Circadian variation in systemic hormone levels in healthy men. Journal of Endocrinological Investigation 19792 131-137.

55 Murono EP, Nankin HR, Lin T \& Osterman J. The aging Leydig cell V. Diurnal rhythms in aged men. Acta Endocrinologica 198299 619-623.

56 Bremner WJ. Vitiello MV \& Prinz PN. Loss of circadian rhythmicity in blood testosterone levels with aging in normal men. Journal of Clinical Endocrinology and Metabolism 198356 1278-1281.

57 Luboshitzky R, Shen-Orr Z \& Herer P. Middle-aged men secrete less testosterone at night than young healthy men. Journal of Clinical Endocrinology and Metabolism 200388 3160-3166.

58 Kley HK, Deselaers T, Peerenboom H \& Kruskemper HL. Enhanced conversion of androstenedione to estrogens in obese males. Journal of Clinical Endocrinology and Metabolism 198051 1128-1132.

59 Kley HK, Edelmann P \& Kruskemper HL. Relationship of plasma sex hormones to different parameters of obesity in male subjects. Metabolism 198029 1041-1045.

60 Hemsell DL, Grodin JM, Brenner PF, Siiteri PK \& MacDonald PC. Plasma precursors of estrogen. II. Correlation of the extent of conversion of plasma androstenedione to estrone with age. Journal of Clinical Endocrinology and Metabolism 197438 476-479.

61 Bulun SE \& Simpson ER. Competitive reverse transcription-polymerase chain reaction analysis indicates that levels of aromatase cytochrome $\mathrm{P} 450$ transcripts in adipose tissue of buttocks, thighs, and abdomen of women increase with advancing age. Journal of Clinical Endocrinology and Metabolism 199478 428-432.

62 Cleland WH, Mendelson CR \& Simpson ER. Effects of aging and obesity on aromatase activity of human adipose cells. Journal of Clinical Endocrinology and Metabolism 198560 174-177.

63 Vermeulen A \& Ando S. Metabolic clearance rate and interconversion of androgens and the influence of the free androgen fraction. Journal of Clinical Endocrinology Metabolism 197948 320-326.

64 Longcope C, Pratt JH, Schneider S \& Fineberg E. Estrogen and androgen dynamics in liver disease. Journal of Endocrinological Investigation $19847629-634$.

Received 3 August 2004

Accepted 18 October 2004 